\title{
A relação entre a Ciência da Informação e a Ciência da Administração
}

\author{
The connection between the pillar of Information \\ science and Management Science
}

\author{
Cláudio Augusto ALVES' \\ Emeide Nobrega DUARTE2
}

\section{Resumo}

Este artigo discorre sobre a saga interdisciplinar entre a Ciência da Informação e a Ciência da Administração. O principal escopo dessa trama se concentra na informação, cujos atributos e propriedades se mesclam entre as duas Ciências. A sua representatividade, no âmbito da Administração, configura-se como recurso organizacional, isto é, como a base e a razão para um novo tipo de gestão - a gestão da informação. O artigo caracteriza-se como estudo exploratório e descritivo, com abordagem qualitativa, do tipo bibliográfico. A interdisciplinaridade entre as duas áreas ocorre de maneira ampla e efetiva, pois os vários conceitos, princípios e metodologias utilizados na Ciência da Administração se mesclam também com a Ciência da Informação em uma ligação do tipo unificadora, pois utiliza conceitos de ambas as Ciências de maneira efetiva. A partir disso, pode-se constatar que a informação é um elemento comum para a construção desse corpus interdisciplinar, bem como é produto passível de administração.

Palavras-chave: Ciência da Administração. Ciência da Informação. Gestão da informação. Informação. Interdisciplinaridade.

\begin{abstract}
The aim of the article is to discuss the interdisciplinary saga between Information Science and Management Science. The main scope of this plot focuses on information, whose attributes and properties are mingled with the two sciences. Its representativeness in Management is designed as an organizational resource, i.e. as the basis and reason for a new type of management - the management of information. This is an exploratory, descriptive and bibliographical study with a qualitative approach. The interdisciplinary nature of these two fields is broad and effective, since several concepts, principles and methodologies used in Management Science mingle with those in Information science as the concepts from both sciences are used effectively. Therefore, information is a common element for building the interdisciplinary corpus, as well as being a product of management.
\end{abstract}

Keywords: Management Science. Information Science. Information management. Information. Interdisciplinarity.

\section{Introdução}

Quando se pensa na Ciência da Informação, vários labores científicos estão relacionados ao seu objeto de estudo. A resposta comum para essa questão identifica a constituição da área na interdisciplinaridade, propondo quadros nocionais tomados de empréstimo de disciplinas tais como a Administração. Essas duas áreas do conhecimento são reconhecidas como Ciência Social Aplicada e, portanto, transcendem as questões teóricas

\footnotetext{
1 Universidade Federal de Campina Grande, Coordenação de Gestão e Desenvolvimento de Pessoas, Secretaria de Recursos Humanos. Campina Grande, PB, Brasil.

2 Universidade Federal da Paraíba, Centro de Ciências Sociais Aplicadas, Departamento de Ciência da Informação. Cidade Universitária, s/n., Castelo Branco, 58000-000, João Pessoa, PB, Brasil. Correspondência para/Correspondence to: E.N. DUARTE. E-mail:<emeide@hotmail.com>

Recebido em 8/10/2013, reapresentado em 20/5/2014 e aceito para publicação em 29/5/2014.
} 
e epistemológicas acerca do território circunstancial de um produto informacional que propicia o desenvolvimento organizacional. Nesses termos, o processo de interligação entre a Ciência da Informação (Cl) e a Ciência da Administração (CA) pode ser verificado na prática.

A informação da qual trata a $\mathrm{Cl}$ movimenta-se num território multifacetado, que pode ser informação tanto em determinada área quanto numa abordagem. Sua representatividade, no âmbito da Administração, prende-se às organizações, pelo fato de elas estarem inseridas em um espaço informacional, que suscita considerar a quantidade de informação e os dados donde ela provém como um importante recurso que necessita e merece ser gerido, ou seja, a conhecida Gestão da Informação $(G I)$.

Nesses aparatos, a 'gestão da informação', concebida como um dos feitos organizacionais que se atribui à informação, é um processo que exige a aplicação de princípios administrativos referentes à aquisição, à organização, ao controle, à disseminação e ao uso da informação para o gerenciamento efetivo das organizações. Tarapanoff (2006) ressalta que, no âmbito da Cl, o principal objetivo é identificar e potencializar os recursos informacionais de uma organização e sua capacidade, visando a sua aprendizagem e adaptação às mudanças ambientais.

Assim, nesse debate, o presente artigo caracteriza-se como estudo exploratório e descritivo, com abordagem qualitativa, do tipo bibliográfico, com o objetivo de apresentar uma reflexão teórica sobre a relação entre a Cl e a CA, com base na informação, especialmente a representatividade desse objeto para a Administração em termos de gestão.

\section{O tear interdisciplinar entre a Ciência da Informação e a Ciência da Administração}

A tônica interdisciplinar da $\mathrm{Cl}$ com a CA ocorre dentro de um processo de trocas de saber, cuja interação navega em problemas básicos de se compreender a aplicação da informação, suas manifestações e o comportamento informativo humano no contexto das organizações. Tais questões, aos olhos de Saracevic (1996), não podem ser resolvidas no âmbito de uma única disciplina, mas numa arena cravada em esforços teóricos, experimentais, profissionais e/ou pragmáticos, que exige conhecimentos de fatos relevantes das áreas disciplinares envolvidas.

González de Gomez (2001) relata que essa situação ocorre a partir do momento em que é preciso resolver uma questão-problema, que exige a coocorrência de diferentes ramos da ciência. Isso seria, segundo a autora, o momento de comunicação, de trocas de saber e de intercâmbio informacional efetivo entre áreas do conhe-cimento antes diferenciadas, que convergem em direção a um problema comum.

A saga interdisciplinar tem característica de uma teia que se forma por diversos campos da ciência, perpassando fronteiras disciplinares que intercambiam informações, noções e teorias, para alcançar um esquema de múltiplas competências. Nesse processo, há todo um emaranhado de conhecimentos, teorias e técnicas que são utilizados nas diversas situações-problema, em que se requer um olhar esforçado para o direcionamento de um mesmo objeto.

Moreira e Moura (2006) afirmam que a Cl se caracteriza por estudos desse tipo, com representação temática híbrida, resultante das especificidades do campo e dos conceitos vindos das fronteiras e de seu domínio. Os autores identificam uma relação de primeiro grau com áreas limítrofes mais próximas, a saber: Administração, Arquivologia, Ciências Cognitivas, Computação, Biblioteconomia, Educação, Economia, Museologia, entre outras. Essa integração mútua se mescla, cientificamente, no labor epistemológico, terminológico, metodológico e comunicacional.

Oliveira (2010) declara que, durante aproximadamente 50 anos de evolução da Ciência da Informação, foram estimuladas discussões e promovidos estudos sobre sua interdisciplinaridade com diversas áreas do conhecimento, entre elas a CA, cuja linha de interação pode ser comprovada em livros, coletâneas, artigos, teses e dissertações. Assim, para conhecimento, seguem alguns exemplos desse elo no Quadro 1.

Nesse quadro representativo, observou-se que as duas Ciências entoam um "dueto", isto é, fazem uma conversa a duas vozes de mesma importância que, em dados momentos, se convergem, sem que uma ou outra perca a sua identidade. Hargreaves (2004) assinala que é um chamado conhecimento geral"transportável", ou seja, 
Quadro 1. Aspectos interdisciplinares entre a Ciência da Informação e a Ciência Administração.

\begin{tabular}{|c|c|c|}
\hline Livro/Artigo/Tese/Dissertação & Autor & Ano \\
\hline Inteligência, informação e conhecimento. & Tarapanoff, Kira & 2006 \\
\hline Gestão estratégica da informação e inteligência competitiva. & Lopes, Jorge Bezerra; Gomes, Elizabeth Braz Pereira; Starec, Claudio & 2006 \\
\hline $\begin{array}{l}\text { A administração da informação integrada às estratégias empre- } \\
\text { sariais. }\end{array}$ & Fidelis, Joubert Roberto Ferreira; Cândido, Cristiane Missias & 2006 \\
\hline Informação, conhecimento e inteligência organizacional. & Valentim, Marta Ligia Pomim & 2007 \\
\hline $\begin{array}{l}\text { A informação como suporte para o planejamento e para a formu- } \\
\text { lação de políticas no setor de transportes. }\end{array}$ & Andrade, Antônio Rodrigues de & 2007 \\
\hline $\begin{array}{l}\text { Estratégias de informação e modelos organizacionais: o espaço } \\
\text { da Administração e da Comunicação na Ciência da Informação. }\end{array}$ & Lima, Regina Célia M. & 2007 \\
\hline $\begin{array}{l}\text { Ciência da Informação e Ciência da Administração: questões } \\
\text { epistemológicas e o fenômeno da informação. }\end{array}$ & Alves, José Alexandre da Costa & 2008 \\
\hline $\begin{array}{l}\text { Análise das relações interdisciplinares daspesquisas científicas } \\
\text { em sistemas de informação. }\end{array}$ & Dias, Fernando Skackauskas & 2008 \\
\hline $\begin{array}{l}\text { Gestão da informação e do conhecimento: origens, polêmicas e } \\
\text { perspectivas. }\end{array}$ & Barbosa, Ricardo Rodrigues & 2008 \\
\hline $\begin{array}{l}\text { Perspectivas metodológicas para o estudoda gestão da infor- } \\
\text { mação em ambientesinformacionais das organizações. }\end{array}$ & Moraes, Cássia Regina Bassan de; Fadel, Bárbara & 2008 \\
\hline $\begin{array}{l}\text { Auditoria da informação e do conhecimento organizacional: gê- } \\
\text { nese de uma integração. }\end{array}$ & Dante, Glória Ponjuán & 2008 \\
\hline $\begin{array}{l}\text { A interdisciplinaridade na formação do administrador: um dueto } \\
\text { entre a Ciência da Informação e a Ciência da Administração. }\end{array}$ & Oliveira, Joaquim Francisco Cavalcante de & 2010 \\
\hline $\begin{array}{l}\text { Informação como objeto para construção do corpus interdis- } \\
\text { ciplinar entre Ciência da Informação e Ciência da Administração. }\end{array}$ & $\begin{array}{l}\text { Oliveira, Joaquim Francisco Cavalcante de; Pinheiro, Lena } \\
\text { Vânia Ribeiro; Andrade, Antônio Rodrigues de }\end{array}$ & 2011 \\
\hline $\begin{array}{l}\text { A gestão da informação e do conhecimento na ciência da infor- } \\
\text { mação: perspectivas teóricas e práticas organizacionais. }\end{array}$ & $\begin{array}{l}\text { Souza, Edivânio Duarte de; Dias, Eduardo José Wense; } \\
\text { Nassif, Mônica Erichsen }\end{array}$ & 2011 \\
\hline $\begin{array}{l}\text { Gestão da informação: estudo comparativo de modelos sob a } \\
\text { perspectiva integrativa dos recursos de informação. }\end{array}$ & Martins, Sergio de Castro; Cianconi, Regina de Barros & 2013 \\
\hline $\begin{array}{l}\text { Gestão do conhecimento científico: proposta de um modelo } \\
\text { para a área de ciência da informação da Universidade Estadual } \\
\text { Paulista (UNESP). }\end{array}$ & Garcia, Cristiane Luiza Salazar; Valentim, Marta Ligia Pomim & 2013 \\
\hline $\begin{array}{l}\text { Inteligência competitiva e as práticas de gestão do conhecimento } \\
\text { no contexto da administração e da ciência da informação. }\end{array}$ & Barrancos, Jacqueline Echeverría; Duarte, Emeide Nóbrega & 2013 \\
\hline
\end{tabular}

Fonte: Elaborado pelos autores, 2013.

não é especificamente de uma única área, uma única empresa ou um único emprego, mas que permeia todo um terreno de facetas da vida econômica, o que se torna um recurso não apenas para o trabalho e a produção.

Em sua tese de doutorado, Andrade (2007), apresentou um trabalho interdisciplinar enfocando a utilização dos conceitos da Cl e da CA, visando contribuir para o entendimento da importância da informação no setor de transportes. $O$ estudo trouxe mais esclarecimentos sobre o uso da informação na gestão estratégica organizacional.
Alves (2008), em sua dissertação de Mestrado, apresentou um capítulo dedicado aos paralelos interdisciplinares da informação entre a Cl e a CA e descreveu uma linha igualitária das abordagens científicas, sob o enfoque das Ciências Sociais, das duas áreas de estudo. Para isso, expôs o modelo de "alto nível" das Ciências Sociais de Burrel e Morgan, o qual oferece uma análise do fenômeno da informação, de acordo com as abordagens 'Paradigmas da informação' (Filosofia da Informação), de Ilharco; 'Paradigmas Epistemológicos da Ciência da Informação', de Capurro, e 'Perspectivas da 
Ciência da Informação', de Saracevic, frente às teorias e às abordagens da CA.

Esse mesmo autor fez uma análise crítica de forma combinada dos paradigmas estudados, com o intuito de explicitar a convergência epistemológica do fenômeno informação, fundamentado por Burrell e Morgan. Nesse sentido, mostra a interligação da Administração com a $\mathrm{Cl}$, utilizando a perspectiva de Saracevic, em conjunto com os três paradigmas da Ciência da Informação apresentados por Capurro, em 1991:físico, cognitivo e social, associados à visão dos paradigmas da informação de Ilharco.

Dias (2008) abordou a interdisciplinaridade em sistemas de informação. Sua pesquisa se realizou a partir de artigos publicados em periódicos internacionais, abrangendo o período de 1985 a 2005. Nos artigos analisados, constatou as relações interdisciplinares entre a $\mathrm{Cl}$, a CA e a Ciência da Computação (CC), em sistemas de informação nessas áreas. Os resultados mostraram a tendência para uma abordagem interdisciplinar entre as áreas, com a seguinte distribuição quanto a publicações de artigos sobre sistemas de informação: Ciência da Informação, com 35\%; Ciência da Administração, com 48\%; e Ciência da Computação, com 17\%.

Em sua tese de doutorado, Oliveira (2010), tratou da interdisciplinaridade entre a $\mathrm{CA}$ e a $\mathrm{Cl}$, com base na informação. $\mathrm{O}$ autor destacou a importância desse elemento no que diz respeito a sua gestão no ambiente organizacional, e elaborou duas propostas: uma referente a um novo currículo para cursos de Administração, e outra, para empresas, a fim de propiciar um ambiente de informação organizacional integrado entre as duas disciplinas.

Autores como Borko (1968), Saracevic (1996) e Oliveira et al. (2011) também apontam o elo básico entre a Cl e a CA, advindo de considerações que se encontram na efetiva gestão dos recursos informacionais no ambiente organizacional. Isso supõe a definição de papéis, a elaboração de estratégias e de instrumentos de análise, a configuração de ambientes, o comportamento, as competências, a cultura, os fluxos, entre outras vinculações que são utilizados amplamente nas duas áreas (Oliveira et al., 2011).

O principal escopo dessa trama interdisciplinar se concentra na informação, que se pode representar graficamente pela Figura 1.

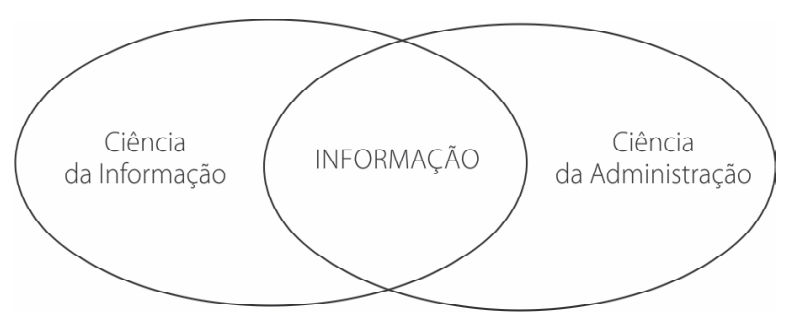

Figura 1. Representação interdisciplinar entre as áreas da Cle da CA. Fonte: Oliveira (2010).

O encontro dessa intersecção se configura em seu papel como recurso organizacional, ou seja, como elemento fundamental, em nível de empresa, na descoberta e na introdução de novas tecnologias, na exploração das oportunidades de investimento e na planificação de toda a atividade industrial. É nessas considerações que palavras-chave da área de Administração se deslocam, combinam e inter-relacionam com a Cl, a saber: efetividade, comunicação humana, conhecimento, registros do conhecimento, informação, necessidades de informação, usos de informação, contexto social, contexto institucional, contexto individual e tecnologia da informação (Saracevic, 1996).

No âmbito das organizações, o estudo da informação assume dimensões oriundas tanto da CA quanto $\mathrm{da} \mathrm{Cl}$, pelo fato de esse recurso ser considerado como principal ativo nos diferentes níveis - estratégico, tático e operacional. O contexto organizacional/informacional envolve atividades comuns que vão desde o planejamento estratégico até o controle operacional, assim como enfoques que dizem respeito à política, à economia, à cognição, à estratégia, ao gerenciamento e ao social, cujos termos são usados em ambas as disciplinas.

Oliveira (2010) tece considerações sobre a interdisciplinaridade dessas duas Ciências, em função da globalização de mercado, de capital e do aumento de competitividade nas empresas, além das Tecnologias de Informação e Comunicação (TIC). Aqui se entende que uma disciplina auxilia a outra no processo de interação e dinamismo da informação na organização, levando como ponto de convergência atributos e propriedades que a CA e a Cl têm, a saber: a gestão da informação, a inteligência competitiva, os regimes de informação, as políticas informacionais e a informação para o conhecimento. 
É importante enfatizar, também, o enriquecimento recíproco das duas áreas no conceito da Gl. O conceito, segundo Oliveira et al. (2011), é fundamental para as duas disciplinas, pois seu entendimento em Administração difere na Ciência da Informação. Na Administração, abrange o processo de coleta, armazenamento, tratamento e disseminação da informação no ambiente organizacional. Já na Ciência da Informação, a Gl abrange os aspectos e as aplicações da informação em geral, pois o ciclo informacional inclui as questões inerentes a partir da identificação das necessidades de informação dos usuários até a etapa de uso da informação.

Andrade (2007) refere que as organizações precisam aprender a gerenciar as informações obtidas de maneira inteligente, de modo que, através de seus processos de inovação, consigam transformá-las em diferencial competitivo. É nesses aparatos que o exercício interdisciplinar da $\mathrm{Cl}$ e da CA implica dizer que o assentamento do espaço da administração na Cl possibilita o entendimento da imbricação transformadora da informação nos ambientes organizacionais, somando-se em abordagens e metodologias que favorecem o alcance de sua representatividade como um recurso de valor para a Administração.

\section{A representatividade da informação no âmbito da administração}

A informação, como objeto fenomenal de estudo da $\mathrm{Cl}$, tem uma representatividade fundamental na Administração. O resultado dessa interação lógica está relacionado a sua inserção na estratégia empresarial, sobretudo, os feitos que objetivam dinamizar as ações econômicas, comerciais, políticas, sociais etc., de modo a propiciar a permanência da organização no mercado em que atuam. Dessa forma, a informação passa a ser valorada de tal forma que justifica o seu papel-chave nas organizações.

A importância que se dá à informação, no contexto organizacional, segundo Beuren (2007, p.43) é:

[...] fundamental no apoio às estratégias e processos de tomada de decisão, bem como no controle das operações empresariais. Sua utilização representa uma intervenção no processo de gestão, podendo, inclusive, provocar mudança organizacional, à medida que afeta os diversos elementos que compõem o sistema de gestão. Esse recurso vital da organização, quando devidamente estruturado, integra as funções das várias unidades da empresa, por meio de diversos sistemas organizacionais.

Os fazeres organizacionais são alicerçados por meio da informação, e sua utilidade tornou-se uma necessidade crescente para qualquer setor de atividade da empresa, devido ao fato de ter a gestão da informação, a tomada de decisão, a informação para o conhecimento e a inteligência estratégica ou competitiva. O núcleo dessa ideia gira em torno da seguinte pergunta: $O$ que queremos fazer com a informação na empresa? Boas intenções se têm em relação a isso, pois o valor econômico advindo da geração, uso e venda da informação está crescendo vertiginosamente, em detrimento do valor agregado pela produção tradicional de bens e serviços.

Davenport (1998) alerta que a informação, assim como as tecnologias que Ihe são associadas, tornou-se um recurso organizacional tão importante quanto as necessidades financeiras e de recursos humanos. A ideia do autor é de que, se há estruturas e processos bem elaborados, políticas, procedimentos, estratégias e visões, consequentemente, os gestores deverão aceitar seu papel como recurso gerador de riquezas.

Choo (2003) ressalta que a informação é mais do que um componente intrínseco de quase tudo o que uma empresa faz, ou seja, é o suporte indispensável de qualquer organização. A imposição desse papel pode ser um fator-chave para se atingir uma situação de excelência na empresa, porquanto quem dispõe de informação potencial, fidedigna, em quantidade adequada e no momento certo, adquire vantagens competitivas. Porém, se falta isso tudo, dá abertura a erros e à perda de oportunidades.

Certamente, para se atingir uma situação de excelência, incita-se a formulação de uma boa estratégia de informação, cuja criação pode abranger todos os aspectos da ecologia da informação, ou seja, "da administração holística da informação, ou da administração informacional centrada no ser humano" (Davenport, 1998, p.44). As estratégias giram em torno de escolhas e de ênfases, que as situam nos tipos de negócio, que produto criar, que mercado atingir. 
Choo (2003) destaca três arenas distintas em que a criação e o uso da informação possuem um papel estratégico no crescimento e na capacidade de adaptação da empresa. Primeiro, a organização usa a informação para dar sentido às mudanças do ambiente externo, pelo fato de as empresas viverem num mundo dinâmico e incerto, onde as forças e a dinâmica do mercado moldam o seu desempenho. Na segunda arena, a organização cria, organiza e processa a informação, de modo a gerar novos conhecimentos por meio do aprendizado, ou seja, novos conhecimentos permitem que ela desenvolva novas capacidades, crie novos produtos e serviços, aperfeiçoe os já existentes e melhore os processos organizacionais. Já a terceira arena é aquela em que as organizações buscam e avaliam informações, de modo a tomar decisões importantes, para que seus objetivos sejam alcançados e tenham espaço garantido no mercado.

A informação transforma os ambientes organizacionais significativamente, e o seu uso exige competências necessárias para saber considerar quais os tipos e qual a sua finalidade para a organização. Moresi (2000) classifica quatro tipo de informação: (a) informação sem interesse: aquela que pode ser dispensada pela organização, pois sua manutenção não agrega valor; (b) informação potencial: aquela que pode levar a uma vantagem competitiva; (c) informação mínima: aquela necessária à gestão da organização; e (d) informação crítica: aquela que garante a sobrevivência da organização.

Lima (2007) afirma que a informação, como recurso organizacional, constitui matéria-prima para o pensamento, a tomada de decisão, a solução de problemas, o desenvolvimento de atitudes, o aprendizado e todas as atividades especificamente relacionadas ao funcionamento e à dinâmica de qualquer empresa. Ressalta-se, ainda, que a informação é considerada o ativo mais importante, o insumo e o produto no processo administrativo de planejar, organizar, controlar, comunicar e coordenar. Portanto, considerar a gestão da infor-mação é, ao mesmo tempo, definir um processo que exige a introdução de uma abordagem interfuncional orientada para a informação.

\section{A informação: objeto passível de administração}

A informação e, mais especificamente, a Gl é o ponto de entrecruzamento entre a $\mathrm{Cl}$ e a $\mathrm{CA}$. O espaço de significação e de produção de sentido que é proporcionado dá abertura à construção de uma nova forma de ver, interpretar, transformar, inovar e modernizar o funcionamento das organizações. A informação, como forma instituída de gestão, assume, hoje em dia, uma importância crescente e de ordem competitiva e estratégica para as empresas.

A gestão é um elemento universal do mundo moderno, que aplica métodos e técnicas com o intuito de alcançar objetivos em um cenário complexo que envolve tomada de decisão, organização, uso da informação e coordenação de múltiplas atividades. Ela está relacionada ao conceito de "administração", do qual é considerada próxima. Drucker (2002, p.22) assinala que, em "última análise, gestão significa a substituição de ideias por ação, do conhecimento por cultura e da cooperação por força".

O ato de gerir se assenta em ações que são desenvolvidas como práticas sistematizadas, para vislumbrar o alcance dos objetivos. Devido à crescente importância para as organizações contemporâneas, a informação passou a ter um merecimento cada vez maior perante os olhos dos gestores, pesquisadores e profissionais. Trabalhar e fazer uso da informação como estratégia de valor para a organização é tê-la como um recurso organizacional que merece ser administrado.

Mas, quais seriam os motivos que levam organizações a ter que gerenciar suas informações? Para Davenport (1998, p.84),"grandes volumes de informação entram e saem das organizações sem que ninguém tenha plena consciência de seu impacto, valor ou custo". Assim, tal gerenciamento é fundamental para a obtenção do sucesso, das oportunidades e da manutenção de vantagem competitiva.

Subjacente a essa ideia, Zorrinho (1995, p.146) assinala que:

[...] gerir a informação é, assim, decidir o que fazer com base em informação e decidir o que fazer sobre informação. É ter a capacidade de selecionar de um repositório de informação disponível aquela que é relevante para uma determinada decisão e, também, construir a estrutura e o design desse repositório.

É nesse sentido que se supõe efetiva necessidade de desenvolver uma boa gestão da informação, para lhe 
dar mais sentido, quando utilizada no papel estratégico de crescimento e capacidade da organização. Braga (2000) ressalta que o objetivo da Gl é apoiar a política global da empresa, na medida em que torna mais eficientes o conhecimento, as práticas informacionais e a articulação entre os vários subsistemas que a constituem.

Em suma, Dias e Belluzzo (2003, p.65) definem a Gl como o"conjunto de conceitos, princípios, métodos e técnicas utilizadas na prática administrativa e colocadas em execução pela liderança de um serviço de informação para atingir a missão e os objetivos fixados". Davenport (1998) busca conciliar tudo o que é necessário para uma boa administração das informações, por meio de um ambiente informacional que abrange: (a) a estratégia da informação que a empresa adota; (b) uma política da informação; (c) a cultura e o comportamento em relação à informação; (d) a equipe de informação; (e) os processos de administração funcional; e (f) a arquitetura da informação.

Choo (2003, p.403) sugere que:

[...] a administração [gestão] da informação seja vista como a administração de uma rede de processos que adquirem, criam, organizam, distribuem e usam a informação. [...] [Assim] analisou o uso da informação organizacional em termos de necessidades, busca e uso da informação.

Somando-se a essa teia de conceitos, Dante (2007, p.19) enuncia que:

La gestión es un proceso, por lo que se definiría La gestión de información como él proceso mediante el cual se obtienen, despliegan o utilizan recursos básicos (económicos, físicos, humanos, ateriales,) para manejar información dentro y para la sociedad a la que sirve. Tiene como elemento básico la gestión del ciclo de vida de este recurso y ocurre en cualquier organización. Es propia también de unidades especializadas que manejan este recurso en forma intensiva, llamadas unidades de información'. El proceso de gestión de información debe ser valorado sistémicamente en diferentes dimensiones y el dominio de sus esencias permite su aplicación en cualquier organización.

A Gestão da Informação é importante para a sobrevivência das organizações, as quais vivem em ambientes dinâmicos e cada vez mais complexos. McGee e Prusak (1994) destacam que, em uma economia onde a informação tem papel importante e de valor, a concorrência entre as organizações é fortemente influenciada por sua capacidade de adquirir, tratar, interpretar e utilizar a informação de forma eficaz. Nesse cenário, informações históricas e atuais, internas ou externas, com qualidade, precisão e relevância tornam-se um diferencial para o sucesso de uma organização frente a clientes cada vez mais exigentes.

Moraes e Fadel (2008) ressaltam que, para se fazer a Gl de uma organização, é necessário estar atento a vários fatores: ao domínio dos diferentes tipos de informações que se manejam na organização; à dinâmica de seus fluxos, formais e informais, representados em diversos processos que transitam em cada informação; ao ciclo de vida de cada informação, incluída a gestão de geração da informação, onde quer que ela ocorra; $\mathrm{e}$ ao conhecimento das pessoas sobre o manejo da informação e da sua cultura informacional.

Para Oliveira e Bertucci (2006), a Gl envolve o "processo da informação", com os seguintes objetivos: promover a eficiência, de forma a organizar e suprir as demandas internas e externas por informação; planejar políticas de informação; desenvolver e manter sistemas e serviços de informação; melhorar o fluxo de informação e o controle da tecnologia da informação.

O sentido que se atribui ao gerenciamento da informação parte de uma perspectiva de "negócio", que contempla as necessidades de informação da própria organização, permitindo uma integração das atividades e dos recursos disponíveis, dos níveis de responsabilidade, das políticas e dos procedimentos a serem adotados, de modo a facilitar o alcance da missão e dos objetivos da organização.

Valentim e Teixeira (2012) assinalam que o ponto central da Gl está em gerenciar a imensa quantidade de informações, provenientes tanto do ambiente interno quanto externo, propiciando seu acesso, compartilhamento e disseminação, por meio de documentos e sistemas, buscando transmitir conhecimento entre indivíduos.

De acordo com McGee e Prusak (1994), Davenport (1998), Choo (2003) e Dias e Belluzzo (2003), o processo de gerenciamento da informação acontece por meio das dimensões apresentadas nos seguintes modelos, conforme Quadro 2. 
Quadro 2. Dimensões que compõem modelos de Gestão da Informação.

\begin{tabular}{|c|c|c|c|}
\hline $\begin{array}{l}\text { Modelo proposto por Choo } \\
(2003)\end{array}$ & $\begin{array}{l}\text { Modelo proposto por Davenport } \\
\text { (1998) }\end{array}$ & $\begin{array}{l}\text { Modelo proposto por McGee e } \\
\text { Prusak (1994) }\end{array}$ & $\begin{array}{l}\text { Modelo proposto por Dias e } \\
\text { Belluzzo (2003) }\end{array}$ \\
\hline $\begin{array}{l}\text { Identificação das necessidades } \\
\text { de informação. }\end{array}$ & $\begin{array}{l}\text { Determinação de exigências de } \\
\text { informação. }\end{array}$ & $\begin{array}{l}\text { Identificação de necessidades e } \\
\text { requisitos de informação. }\end{array}$ & $\begin{array}{l}\text { Sensibilização da necessidade de } \\
\text { informação. }\end{array}$ \\
\hline Aquisição de informação. & Obtenção de informação. & Aquisição e coleta de informação. & Estruturação adequada. \\
\hline $\begin{array}{l}\text { Organização e armazenamento } \\
\text { da informação. }\end{array}$ & Distribuição da informação. & $\begin{array}{l}\text { Classificação, armazenamento, } \\
\text { tratamento e apresentação da } \\
\text { informação. }\end{array}$ & $\begin{array}{l}\text { Elaborar plano de gestão da } \\
\text { informação. }\end{array}$ \\
\hline $\begin{array}{l}\text { Desenvolvimento de produtos e } \\
\text { serviços informacionais. }\end{array}$ & Utilização da informação. & $\begin{array}{l}\text { Desenvolvimento de produtos e } \\
\text { serviços de informação. }\end{array}$ & \\
\hline Distribuição da informação. & & $\begin{array}{l}\text { Distribuição e disseminação da } \\
\text { informação. }\end{array}$ & \\
\hline Uso da informação. & & Análise e uso da informação. & \\
\hline
\end{tabular}

Fonte: Adaptado de Souza e Duarte, 2011.

A partir dos modelos propostos pelos autores acima referidos, Souza e Duarte (2011), em achados de pesquisa descobriram que, além daquelas dimensões, outros elementos se destacavam nas produções científicas do Encontro Nacional de Pesquisa em Ciência da Informação, tais como: busca, seleção, recuperação, acesso e compartilhamento da informação, como indicadores de Gl.

Esse processo se vislumbra no sentido de que a informação, quando criada, organizada e processada pela organização, passe a ter um valor estratégico e produtivo em seu mundo dinâmico e incerto. O que é construído nas organizações, através do uso da informação e como principal ingrediente de competitividade, é transformado em conhecimento, em estratégia empresarial. Nesse contexto, o uso da informação, no que tange à competitividade e à estratégia, traduz-se como um papel de apoio em aproveitar oportunidades de mercado, dominar os riscos ou se submeter a eles com todas as incertezas que acarretam.

Na gestão de uma unidade econômica cujo objetivo é gerar produtos ou serviços, é necessário obter informação em três níveis, segundo Anthony (1965): (a) Nível estratégico: situado no topo da pirâmide de uma hierarquia organizacional. Aqui, são tomadas decisões estratégicas, com informações variadas, complexas e seguras, advindas de fontes externas à organização e de outros níveis hierárquicos. São decisões tomadas a partir de uma gama de informações que definem objetivos, políticas e diretrizes organizacionais; (b) Nível tático: é considerado um nível intermediário, que abriga as decisões táticas e exige informação pormenorizada, com alguma triagem e responsabilidades na interpretação da informação, que provém de fontes internas e é obtida com alguma frequência; (c) Nível operacional: aqui são tomadas as decisões operacionais para problemas bem definidos, sendo necessárias informações bem claras, provenientes, essencialmente, do sistema interno, com vista a ações imediatas.

O papel da gestão da informação, nesse caso, é auxiliar e apoiar os níveis estratégico, tático e operacional, vislumbrando a eficácia informacional em todos eles. É aderir a uma nova postura em relação à informação, no que tange à coordenação eficaz em processos de recursos humanos, comunicação, aprendizagem, inovação e redução de custos.

Para Amorim e Tomaél (2011), esse tipo de gestão aprimorou a forma de controlar a explosão de informações circulante entre os níveis, considerando a complexidade crescente de decisão para melhorar o fluxo, controle, análise e síntese de informação para os tomadores de decisão.

Da observação desse cenário, também é importante destacar, segundo Bergeron (1996), a necessidade de se adotarem medidas de Gestão de Recursos Informacionais (GRI) como resposta aos problemas que as organizações enfrentam. Se considerar a informação como qualquer outro recurso da empresa, seja ele material, 
financeiro ou humano, deve ser administrado de forma que atinja os resultados esperados. Para Oliveira (2010), os termos clareza, confiabilidade, utilidade e precisão, juntamente com outros, formam um grupo de atributos indispensáveis para esse tipo de gestão no ambiente organizacional.

Assim, a gestão da informação, no ambiente organizacional, corresponde às estratégias de ação e ao conjunto de políticas que identificam as necessidades informacionais, a prospecção, o monitoramento, a análise e a disseminação, com valor agregado tanto para os colaboradores quanto para a própria empresa.

\section{Conclusão}

A saga interdisciplinar entre a Ciência da Informação e a Ciência da Administração só foi possível em razão do elemento comum às duas áreas: a informação, que é enfatizada pelos estudos dos que se ocupam da seleção, organização, gerência, disseminação, recuperação e uso da informação, além da administração, estratégia e marketing da informação. Essa interligação funcional vigora na prática e em atributos que, minuciosamente, definem os caminhos de intersecção dessas duas ciências.

A interdisciplinaridade entre as duas áreas ocorre de maneira ampla e efetiva, pois os vários conceitos, princípios e metodologias utilizados na Ciência da Admi-

\section{Referências}

Alves, J.A.C. Ciência da Informação e Ciência da Administração: questões epistemológicas e o fenômeno da Informação. 2008. Dissertação (Mestrado em Ciência da Informação) - Instituto Brasileiro de Informação em Ciência e Tecnologia, Universidade Federal Fluminense, Niterói, 2008.

Amorim, F.B.; Tomaél, M.I. Gestão da informação e gestão do conhecimento na prática organizacional: análise de estudos de casos. Revista Digital de Biblioteconomia e Ciência da Informação, v.8, n.2, p.1-22, 2011. . Disponível em: <http:// www. sbu.unicamp.br/seer/ojs/index.php/rbci> Acesso em: 13 nov. 2013.

Andrade, A.R. A informação como suporte para o planejamento e para a formulação de políticas no setor de transportes. 2007. Tese (Doutorado em Ciências de Engenharia de Transporte) Instituto Alberto Luiz Coimbra de Pós-Graduação e Pesquisa de Engenharia, Universidade Federal do Rio de Janeiro, Rio de Janeiro, 2007. nistração se mesclam também com a Ciência da Informação. Assim, pode-se dizer que é uma ligação do tipo unificadora, pois utiliza conceitos de ambas as Ciências de maneira efetiva. Estudos científicos ainda são pouco disponíveis na área da $\mathrm{Cl}$, mas esta já se mostra mais significativa do que foi até então, e os resultados indicam uma tendência de intensificação.

A informação, objeto de estudo da Cl, é tida na Administração como recurso organizacional que gera valor produtivo e de capital para as organizações. É o elo que constitui matéria-prima para informar e para administrar a sua aplicação.

O ambiente de informação organizacional permite a utilização de diversas atividades ligadas a ela, criando ligações interdisciplinares em busca de soluções corporativas para os diversos problemas organizacionais, tais como: gestão estratégica da informação, aprendizagem organizacional, gestão do conhecimento e inteligência competitiva. A administração informacional indica o gerenciamento da informação como um processo organizacional, que enfatiza a mensurabilidade e o aperfeiçoamento da informação na empresa. Gerir a informação exige a introdução de uma abordagem interfuncional, com métodos, ferramentas e técnicas de uma variedade de funções orientadas para a informação. Portanto, caminha-se para o entendimento de que a informação é insumo e produto, tanto para construir o corpus interdisciplinar entre a $\mathrm{Cl}$ e a $\mathrm{CA}$, quanto para gerir.
Anthony, R.N. Planning and control systems: A framework for analysis. Cambridge: Harvard University Press, 1965.

Barbosa, R.R. Gestão da informação e do conhecimento: origens, polêmicas e perspectivas. Informação \& Informação, v.13, n.(Esp). p.1-25, 2008

Beuren, I.M. Gerenciamento da Informação: um recurso estratégico no processo da gestão empresarial. 2.ed. São Paulo: Atlas, 2007.

Bergeron, P. Information resources management. Annual Review of Information Science and Technology, v.31, p.263-300, 1996.

Borko, H. Information science: What is it? American Documentation, v.19, n.1, p.3-5, 1968.

Braga, A. A gestão da informação. Millenium, v.19, 2000. Disponível em:<http://repositorio.ipv.pt/bitstream/10400.19/903/ 
1/A\%20GEST\%C3\%830\%20DA\%20INFORMA\%C3\%87\% C3\%83O.pdf>. Acesso em: 12 ago. 2013.

Choo, W. A organização do conhecimento: como as organizações usam a informação para criar significado, construir conhecimento e tomar decisões. São Paulo: Senac, 2003.

Dante, G.P. Gestión de información: dimensiones e implementación para el éxito organizacional. Gijón:Trea, 2007. Disponible en: <http://dialnet.unirioja.es/servlet/revista? codigo $=11860>$. Acceso en: 26 abr. 2014.

Dante, G.P. Auditoria da informação e do conhecimento organizacional: gênese de uma integração. Brazilian Journal of Information Science, v.2, n.2, 2008. Disponível em: <http:// www.bjis.unesp.br/pt/>. Acesso em: 26 abr. 2014

Davenport, T. Ecologia da informação: por que só a tecnologia não basta para o sucesso na era da informação. São Paulo: Futura, 1998.

Dias, F.S. Análise das relações interdisciplinares das pesquisas científicas em sistemas de informação. Perspectivas em Ciência da Informação, v.13, n.1, p.199-215, 2008.

Dias, M.M.K.; Belluzzo, R.C.B. Gestão da informação em ciência e tecnologia sob a ótica do cliente. São Paulo: EdUSC, 2003.

Drucker, P. O melhor de Peter Drucker: a administração. São Paulo: Nobel, 2002.

Fidelis, J.R.F.; Cândido, C.M. A administração da informação integrada às estratégias empresariais. Perspectivas em Ciência da Informação, v.11 n.3, p.424-432, 2006.

Garcia, C.L.S.; Valentim, M.L.P. Gestão do conhecimento científico: proposta de um modelo para a área de ciência da informação da universidade estadual paulista (Unesp). In: Encontro Nacional de Pesquisa em Ciência da Informação, 14., 2013. Florianópolis. Anais... Santa Catarina: Universidade Federal de Santa Catarina, 2013. p.1-20.

González de Gomes, M.N. Interdisciplinaridade e Ciência da Informação: de característica a critério delineador de seu núcleo principal. DataGramaZero: Revista da ciência da informação, v.2, n.4, 2001. Disponível em: <http://www. dgz.org.br/ago01/F_I_art.htm>. Acesso em: 17 jun. 2012.

Hargreaves, A. O ensino na sociedade do conhecimento: educação na era da insegurança. Porto Alegre: Artmed, 2004.

Lima, R.C.M. Estratégias de informação e modelos organizacionais: o espaço da administração e da comunicação na ciência da informação. Rio de Janeiro: E-papers, 2007.

Lopes, J.B.; Gomes, E.B.P.; Starec, C. Gestão estratégica da informação e inteligência competitiva. Rio de Janeiro: Saraiva, 2006.

McGee, J.; Prusak, L. Gerenciamento estratégico da informação: aumente a competitividade e a eficiência de sua empresa utilizando a informação como ferramenta estratégica. 8.ed. Rio de Janeiro: Campus, 1994.

Martins, S.C.; Cianconi, R.B. Gestão da informação: estudo comparativo de modelos sob a perspectiva integrativa dos recursos de informação. In: Encontro Nacional de Pesquisa em Ciência da Informação, 14., 2013. Florianópolis. Anais.. Santa Catarina: Universidade Federal de Santa Catarina, p.1-6, 2013.

Moraes, C.R.B.; Fadel, B. Perspectivas metodológicas para o estudo da gestão da informação em ambientes informacionais das organizações. Ibersid, v.2, p.33-42, 2008.

Moreira, M.P.; Moura, M.A. Construindo tesauros a partir de tesauros existentes: a experiência do TCl - Tesauro em Cl. DataGramaZero: Revista da Ciência da Informação, v.7, n.4, p.1-23, 2006. Disponível em: <www.dgz.org.br>. Acesso em: 24 abr. 2014.

Moresi, E. Delineando o valor do sistema de informação de uma organização. Ciência da Informação, v.29, n.1, p.14-24, 2000. Disponível em: <http://revista.ibict.br/index. php/ciinf/ article/viewArticle/246>. Acesso em: 9 dez. 2008.

Oliveira, J.F.C. A interdisciplinaridade na formação do administrador: um dueto entre a Ciência da Informação e a Ciência da Administração. 2010. Tese (Doutorado em Ciência da Informação) - Instituto de Arte e Comunicação Social, Universidade Federal Fluminense, Niterói, 2010.

Oliveira, J.F.C.; Pinheiro, L.V.R.; Andrade, A.R. Informação como objeto para construção do corpus interdisciplinar entre Ciência da Informação e Ciência da Administração. Liinc em Revista, v.7, n.1, p.61-81, 2011

Oliveira, M.; Bertucci, M.G.E.S. A pequena e média empresa e a gestão da informação. 2006. Disponível em: <http://www. sebrae.com.br/sites/PortalSebrae/solucoes_online/BibliotecaSebrae:-publicações,-cartilhas-e-guias>. Acesso em: 24 abr. 2014.

Saracevic, T. Ciência da informação: origem, evolução e relações. Perspectivas em Ciência da Informação, v.1, n.1, p.41-62, 1996.

Souza, I.G.C.O.; Duarte, E.N. Dimensões de um modelo de gestão da informação no campo da ciência da informação: uma revelação da produção científica do Enancib. Liinc em Revista, v.7, n.1, p.152-169, 2011.

Souza, E.D.; Dias, E.J.W.; Nassif, M.E. A gestão da informação e do conhecimento na ciência da informação: perspectivas teóricas e práticas organizacionais. Informação \& Sociedade: Estudos, v.21, n.1, p.55-70, 2011.

Tarapanoff, K. Informação, conhecimento e inteligência em corporações: relações e complementaridade. In: Tarapanoff, K. Inteligência, informação e conhecimento. Brasília: Ibict, p.19-35, 2006.

Valentim, M.L.P.; Teixeira, T.M.C. Fluxos de informação e linguagem em ambientes organizacionais. Informação \& Sociedade: Estudos, v.22, n.2, p.151-156, 2012.

Valentim, M.L.P. Informação, Conhecimento e inteligência organizacional. 2.ed. Marília: Fundepe, 2007.

Zorrinho, C. Gestão da informação: condição para vencer. Lisboa: lapmei, 1995. 